IZA DP No. 7092

The Effect of Tip Credits on Earnings and Employment in the U.S. Restaurant Industry

William E. Even

David A. Macpherson

December 2012 


\title{
The Effect of Tip Credits on Earnings and Employment in the U.S. Restaurant Industry
}

\author{
William E. Even \\ Miami University \\ and IZA \\ David A. Macpherson \\ Trinity University \\ and IZA \\ Discussion Paper No. 7092 \\ December 2012 \\ IZA
P.O. Box 7240
53072 Bonn
Germany \\ Phone: +49-228-3894-0 \\ Fax: +49-228-3894-180 \\ E-mail: iza@iza.org
}

\begin{abstract}
Any opinions expressed here are those of the author(s) and not those of IZA. Research published in this series may include views on policy, but the institute itself takes no institutional policy positions. The IZA research network is committed to the IZA Guiding Principles of Research Integrity.

The Institute for the Study of Labor (IZA) in Bonn is a local and virtual international research center and a place of communication between science, politics and business. IZA is an independent nonprofit organization supported by Deutsche Post Foundation. The center is associated with the University of Bonn and offers a stimulating research environment through its international network, workshops and conferences, data service, project support, research visits and doctoral program. IZA engages in (i) original and internationally competitive research in all fields of labor economics, (ii) development of policy concepts, and (iii) dissemination of research results and concepts to the interested public.
\end{abstract}

IZA Discussion Papers often represent preliminary work and are circulated to encourage discussion. Citation of such a paper should account for its provisional character. A revised version may be available directly from the author. 
IZA Discussion Paper No. 7092

December 2012

\section{ABSTRACT \\ The Effect of Tip Credits on Earnings and Employment in the U.S. Restaurant Industry}

According to federal law in 2012, employers can take a credit of up to $\$ 5.13$ for tips received by workers in satisfying the minimum wage requirement of $\$ 7.25$. This study uses interstate variation in laws regarding tip credits and minimum wages to identify the effects of reducing or eliminating the tip credit on employment and earnings in the U.S. restaurant industry. Using data from the Quarterly Census of Employment and Wages and the Current Population Survey, we find that a reduction in the tip credit increases weekly earnings but reduces employment in the full services restaurant industry and for tipped workers. The results are robust to controls for spatial heterogeneity in employment trends and are supported by a series of falsification tests.

JEL Classification: J30, J31, J38

Keywords: tip credit, minimum wage, tipped workers, cash wage, earnings, employment

Corresponding author:

David A. Macpherson

Department of Economics

Trinity University

San Antonio, TX 78212

USA

E-mail: David.Macpherson@trinity.edu 


\section{Introduction}

In 2011, the U.S. restaurant industry employed nearly 9 million workers and accounted for nearly one-half of all hourly workers in the U.S. that were paid at or below the federal minimum wage. ${ }^{1}$ Because of the sheer size of the industry and the number of its workers that are affected by minimum wage laws, many studies of the earnings and employment effects of minimum wages have focused on the restaurant industry. Most of this research, however, has focused on the limited service restaurant industry because of a special provision in the federal law that full service restaurants can take advantage of - the "tip credit”. As of 2012, federal law requires a minimum wage of $\$ 7.25$, but employers of tipped workers may take a credit of up to $\$ 5.12$ per hour against the minimum wage requirement. Put in other words, the law allows an employer to pay a “cash wage” of \$2.13 per hour so long as the worker earns sufficient tips to make up the difference between the cash wage and the minimum wage.

While the federal cash wage has remained at \$2.13 since April 1991, 31 states currently require a cash wage above $\$ 2.13$ and 7 states disallow any tip credit and set the cash wage equal to the minimum wage. Also, there have been several legislative efforts to raise the federal cash wage. Most recently, the Rebuild America Act, introduced as H.R. 5727, would gradually increase the federal cash wage to 70 percent of the federal minimum wage.

This study uses data from two different sources -- the Quarterly Census of Employment and Wages (QCEW) and the Current Population Survey (CPS) -- to estimate the effects of changes in the cash wage on earnings and employment in the restaurant industry. The QCEW data provides information on employment and earnings by state and industry. Since workers at limited service restaurants are rarely eligible for tips, we use the QCEW to estimate the effect of changes in cash wages in the full service restaurant industry. The limited service industry is used as a comparison group to assure that our results

\footnotetext{
${ }^{1}$ The employment estimate is from the Bureau of Labor Statistics (BLS) Current Employment Statistics (http://www.bls.gov/ces). Estimates of the number of workers earning at or below the minimum wage by industry is also available from the BLS at http://www.bls.gov/cps/minwage2011tbls.htm\#5 .
} 
are not driven by unobserved factors that might drive employment or earnings in both parts of the restaurant industry. The CPS data provides information on a worker's industry of employment, but does not separately identify full- from limited-service restaurants. The CPS does, however, provide information on hours worked and occupation. This allows us to examine the effect of higher cash wages on hours of restaurant industry employees separately for tipped and non-tipped workers.

Using QCEW data, we find fairly robust evidence that higher cash wages improve earnings of full service restaurant workers, but have no effect for limited service restaurant workers. Estimation of employment and hours effects is more challenging. We implement several strategies to isolate the employment effects, test the robustness of results to sample periods and spatial heterogeneity, and provide falsification tests to be sure that our results are not spurious. Overall, the bulk of the evidence suggests that higher cash wages reduce the employment and hours of workers who are eligible for a tip-credit. Moreover, we find fairly strong evidence that the results are not due to omitted variables that cause a spurious relationship between a state’s cash wage and employment levels.

\section{Background}

The vast majority of the existing research on the effects of the minimum wage on employment in the restaurant industry focuses on limited service restaurants because of the complexities created by tip credits in the full service industry. ${ }^{2}$ While full service restaurants are subject to the same minimum wage requirements as other industries, federal law allows employers to meet some of the minimum wage requirement by taking a credit for tips earned by their workers.

Between 1990 and 2012, federal law increased the minimum wage from \$3.35 to \$7.25 in seven steps. Over the same period, numerous states passed laws increasing their minimum wage above the

\footnotetext{
${ }^{2}$ Studies focusing on the effects of minimum wages on the limited services restaurant industry include, for example, Card and Krueger (1995, 2000); Neumark and Wascher (2000, 2008), Aaronson and French (2007), Aaronson et al. (2008), Dube et al (2010).
} 
federal level. The result was a substantial increase in the interstate variation in minimum wages. The standard deviation of minimum wages across states tripled between 1990 and 2007, but has fallen since then as the \$2.10 increase in the federal minimum between 2007 and 2009 reduced interstate variation. Over the past 20 years, interstate variation in the cash wage has increased steadily over time. While the federal cash wage has remained at \$2.13 since 1991, there has been a steady increase in the number of states with cash wages above the federal level.

The theoretical effects of a higher minimum wage on earnings and employment have been described in numerous studies. If the labor market is competitive, an increase in the minimum wage reduces employment of workers previously earning the minimum, but could increase or decrease aggregate earnings of the affected workers depending upon the elasticity of labor demand. If, on the other hand, the labor market is monopsonistic, small increases in the minimum wage could increase both employment and earnings of affected workers, but sufficiently large increases in the minimum reduce employment. $^{3}$

A simple extension of the competitive model suggests that increases in the cash wage (i.e., a reduction in the tip credit) would reduce the employment of workers eligible for a tip credit and, depending on the elasticity of labor demand, could either increase or decrease total earnings in the industry. The standard competitive model, however, ignores several possible employer responses to an increase in the cash wage that could mitigate any effect. For example, suppose that an increase the cash wage leads to rents (i.e., wages in excess of their reservation wage) for tipped workers. Employers can offset the increased cost of higher cash wages by requiring tip-pooling which would take some of the tips away from the tipped workers and redistribute them to other workers. Since the other workers now receive a share of the tips, the employer can reduce their wages and offset the costs of the higher cash wage. There are several limits to the tip-pooling strategy, however. For example, federal law requires

\footnotetext{
${ }^{3}$ See McConnell, Brue, and Macpherson (2010), pp. 397-403,
} 
that only "regularly tipped" workers be included in a mandatory tip pool. ${ }^{4}$ "Back of the house" staff who do not regularly engage with customers such as cooks, dishwashers, and janitors do not qualify. ${ }^{5}$ Over the years, there have been numerous lawsuits over tip-pooling requirements. [Ahmed (2009)]. These include rulings that salad preparers and workers with managerial responsibilities cannot be included in the tip pool, but bartenders can. Other lawsuits addressed the validity of the tip pooling formula at specific restaurants. Courts have also upheld the notion that a "service charge is not a tip, and thus employers can keep part or all of service charges. ${ }^{6}$

Another limit to the effectiveness of the tip-pooling strategy is that, even if tips are shared with other workers, minimum wage restrictions may limit the employer's ability to reduce their wages particularly if the cash wage rises to the level of the minimum wage. If, for example, bussers are paid the minimum wage without tips and a mandatory tip-pool is introduced, the employer can reduce the bussers wage below the minimum wage only if there is a tip credit allowed in the state.

If tip-pooling is not a viable option for offsetting the effect of a higher cash wage, an employer could attempt to mitigate the effect on labor costs by requiring each server to perform more non-tipped work. This is essentially the same as mandating tip pooling, except that the pooling occurs by requiring servers to hold "dual jobs” so that tips earned while performing the tipped job can be used to generate a tip credit for hours when they perform the non-tipped job. Examples of such strategies would include the requirement that servers clean their own tables or prepare the salads for their customers; or that servers stay after the restaurant is closed to assist with cleaning. As with tip sharing across workers, this

${ }^{4}$ The Department of Labor defines a "tipped employee" as someone that customarily and regularly receives at least $\$ 30$ per month in tips. In practice, this has been interpreted to include waiters/waitresses, counter personnel who serve customers; server helpers (bussers); and service bartenders. Robinson (2011) provides a good review of federal law on tip pooling. If the tip pool is voluntary, there are no restrictions on who the worker can share the tips with. The Department of Labor defines a "tipped employee" as someone that customarily and regularly receives at least \$30 per month in tips. In practice, this has been interpreted to include waiters/waitresses, counter personnel who serve customers; server helpers (busboys/girls); and service bartenders.

${ }^{5}$ An interesting exception to the rule that cooks cannot be included in the tip pool was made for sushi chefs since they interact with customers. http://waiterpay.com/japanese-restaurants-hit-by-wave-of-overtime-and-tip-stealingcases.

${ }^{6}$ If the restaurant does not make it clear to the customer that the added charge is a "service charge" (e.g., if it is listed as a gratuity), the employee may be entitled to the payments. See the court cases discussed in Ahmed (2009) for a discussion of this point. 
strategy becomes less effective when the cash wage approaches the minimum wage unless some nontipped workers were initially being paid above the minimum wage. Also, the federal government places restrictions on an employer's ability to receive a tip credit for a worker with dual jobs. ${ }^{7}$

While the predicted effects of a higher cash wage are fairly straightforward in the competitive model, Wessels (1997) suggests that the assumption of a competitive labor market might not be appropriate for tipped workers. The logic is that an increase in the number of workers in the restaurant industry, ceteris paribus, reduces tips per hour and must thus be offset by higher wages to retain workers resulting in monopsonistic conditions. As a result, increases in the cash wage could lead to an increase in employment, though a sufficiently large increase would reduce employment.

In sum, the theoretical effects of a higher cash wage on earnings and employment depend critically on whether (a) the employer can use tip pooling or dual jobs to offset the effects, or (b) the restaurant industry is a monopsony. If the restaurant industry is competitive and the employer is unable to mitigate the effects of higher cash wages through tip pooling or dual jobs, a higher cash wage drives up the cost of tipped workers and should have the same effect as an increase in the minimum wage - fewer hours of employment, an increase in hourly earnings, but an ambiguous effect on aggregate labor earnings in the industry. If the restaurant industry is a monopsony, a higher cash wage could lead to an increase in employment - but a sufficiently large increase in the cash wage would reduce employment. Given the wide range of possible outcomes, the effect of higher cash wages becomes an empirical question.

While numerous studies examine the effect of minimum wage increases on employment in the limited services restaurant industry, few studies examine the effect of higher cash wages in the fullservices industry. Wessels (1993) performs a cross-sectional analysis of restaurant employment (full and limited service combined) using data from the 1987 Census of Retail Trade and finds that increases in

\footnotetext{
${ }^{7}$ The Department of Labor limits an employer's ability to take a tip credit for the hours that a person does nontipped work. For example, if a server is required to spend a significant share of his or her time cleaning the restaurant before opening or after closing, the employer may be prohibited from taking a tip credit for the hours the worker is cleaning. It is more difficult, however, to restrict an employer's ability to require a server to perform dual tasks (such as serving and cleaning tables) where the line between tipped and non-tipped work is less clear. See Robinson (2011) for a discussion of "dual jobs” versus "related duties”.
} 
either the minimum wage or cash wage reduce restaurant employment. The cash wage elasticity of employment is estimated to be -0.15 implying that a 10 percent increase in the cash wage reduces employment at restaurants by 1.5 percent. A potential concern with this study is that it is based on crosssectional data. Consequently, if there are unobserved differences across states that affect both their law on cash wages and restaurant industry employment, the estimated effect of cash wages will be biased. Wessels (1997) uses panel data on restaurant employment (full and limited service combined) from 1977, 1982, and 1987 to estimate the effect of higher cash wages. Consistent with the predictions of his monopsonistic model, he finds that higher cash wages increase employment at full service restaurants when the cash wage is low, but sufficiently large increases in the cash wage reduce employment.

The effect of cash wages on earnings in the restaurant industry have been examined by two studies. Anderson and Bodverson (2005) use 1999 earnings data on state-specific measures of hourly compensation for waiters, waitresses, and bartenders and report that, controlling for economic conditions and worker characteristics, higher cash wages have no effect on hourly compensation (wages plus tips) for these tipped workers.

Using data from the 2008-2009 Current Population Survey, Allegretto and Filion (2011) find that servers who live in states with a higher cash wage also have higher hourly wages (including tips). While this conflicts with Anderson and Bodverson (2005), the two studies use different data sources and Allegretto and Filion do not control for other factors that might influence earnings and a state’s cash wage. For example, if states with higher earnings levels (perhaps due to a higher cost of living) are more likely to have cash wages above the federal level, a spurious relationship would be found between cash wages and earnings. 


\section{Data}

The Quarterly Census of Employment and Wages (QCEW) is the first source of data for our analysis. This dataset provides a quarterly count of employment and payroll reported by employers and covers 98 percent of U.S. jobs. The quarterly counts are available at the county, state, and national levels by industry. ${ }^{8} \quad$ The data provides a complete tabulation of employment and earnings for workers covered by either state or federal unemployment insurance programs.

Our study uses state-level QCEW data on private sector employment from 1990 through 2011 to investigate how changes in the minimum and cash wage affect private sector employment in the full service restaurant industry (NAICS code 7221). We expect changes in the cash wage will have the largest effect on full service restaurants since a large share of their workers are eligible for tips. As a point of comparison, we also consider effects on limited service restaurants (NAICS 722211) where few workers are likely to receive tips and cash wages should have a minimal effect on labor cost. ${ }^{9} \quad$ As an illustration of the significant differential in the share of workers eligible for tips, the Occupational Employment Survey for May 2011 indicates that the percentage of employees in occupations generally eligible for tips is 55 percent at full service restaurants, but only 4 percent at limited service restaurants. ${ }^{10}$ The primary advantage of the QCEW data is that it covers all workers covered by state or federal unemployment insurance and thus provides a very accurate estimate of employment and payroll. While the QCEW censors state-specific data for confidentiality reasons when an industry's employment count is too small, both the limited and full services restaurant industries are sufficiently large that there are no

\footnotetext{
${ }^{8}$ For more details on the QCEW, see http://www.bls.gov/cew/ .

${ }^{9}$ According the Census Bureau industry definitions, full service restaurants are "primarily engaged in providing food services to patrons who order and are served while seated (i.e., waiter/waitress service) and pay after eating." Limited service restaurants provide food services ... where patrons generally order or select items and pay before eating." See http://www.census.gov/econ/industry/ for a complete list of NAICS industry definitions.

${ }^{10}$ Occupations that we count as eligible for tips include waiters and waitresses, dining room attendants, bartenders, bartender helpers, and hosts and hostesses. See http://www.bls.gov/oes/ for occupational employment statistics.
} 
censored data for any state or quarter. A shortcoming of the data is that it does not provide any information about work hours or the characteristics of the workers in the industry.

Our second data source is the Current Population Survey (CPS) from 1990 through 2011. This dataset is monthly. An advantage of the CPS is that it provides work hours and occupation for each worker. There are, however, two shortcomings relative to the QCEW. First, the CPS represents a stratified random sample of approximately 60,000 U.S. households in every month. Consequently, sample weights must be used to estimate employment or hours and the sample sizes for the restaurant industry for some states in a given month can be small. This may potentially lead to significant sampling error in the estimates of employment or hours. To address this issue, we pool our data and generate quarterly estimates of state employment and estimate regressions with weighting by state population to account for greater precision in the employment estimates for the larger states. Standard errors for the regression coefficients are calculated with corrections for clustering by state to allow for the possibility of heteroskedasticity or correlation of errors across time within a state. The second shortcoming of the CPS relative to the QCEW is that the industry codes do not distinguish between full- and limited-service restaurants. As a result, we use occupational classifications to sort workers according to whether they are likely to be eligible for a tip credit.

Our data on state cash wages are obtained from a variety of sources including Wessels (1993, 1997), legislative updates published in the Monthly Labor Review for early years, research documents from the Employment Policies Institute, and the Department of Labor website. ${ }^{11}$ To get a sense of the overall trend in the cash wage, Figure 1 plots the number of states (counting Washington D.C. as a state) that require a cash wage above the federal cash wage between 1990 and 2011. The number of states with cash wages above the federal level rose from 15 in January of 1990 to 31 in December of 2011. Figure 2 plots the average cash wage across the 50 states and Washington, D.C. and shows that the average cash

\footnotetext{
${ }^{11}$ The BLS provides minimum wages for tipped workers by state for 2009 through 2011 at http://www.dol.gov/whd/state/tipped.htm . Minimum and cash wages are given for each state for 1990 and 2011 in appendix table 1.
} 
wage rose from $\$ 2.25$ to $\$ 4.04$ since 1990 . There were particularly large increases in the average cash wage in October 1996 when 7 states increased their cash wage above the federal level for the first time, and again in January 2007 when 5 additional states pushed above the federal level for the first time. In 20 states, the cash wage is now tied directly to the minimum wage so that the cash wage rises whenever the minimum wage rises.

\section{Empirical Analysis.}

To examine the effect of higher cash wages on employment or earnings in the restaurant industry, we use a regression version of difference-in-difference (DD) estimation common in studies of the employment effects of minimum wage increases. ${ }^{12}$ The regression equation is as follows:

$$
\mathrm{Y}_{\mathrm{it}}=\alpha_{0}+\mathrm{MW}_{\mathrm{it}} \beta_{1}+\mathrm{CW} \beta_{2}+\mathrm{X}_{\mathrm{it}} \gamma+\lambda_{\mathrm{t}}+\mathrm{S}_{\mathrm{i}}+\varepsilon_{\mathrm{it}}
$$

where the subscripts $i$ and $t$ represent state and quarter, respectively, $\mathrm{Y}$ is the log of a measure of employment or earnings in a sector of the restaurant industry, $M W$ is the log of the effective minimum wage (i.e., the greater of the federal or state minimum wage), $C W$ is the log of the effective cash wage, $\mathrm{X}_{\mathrm{it}}$ is a vector of control variables reflecting economic conditions, seasonal dummy variables, and population demographics that would affect earnings or employment in the industry, $\lambda_{t}$ represent time fixed effects for each quarter, $S_{i}$ represent state fixed effects; and $\boldsymbol{\varepsilon}_{\boldsymbol{i}}$ is an error term.

The elasticities of the relevant dependent variable with respect to the minimum and cash wage are $\beta_{1}$ and $\beta_{2}$. If, for example, the elasticity of employment with respect to the cash wage $\left(\beta_{2}\right)$ is -0.2 , a 10 percent increase in the minimum wage causes a 2 percent decrease in employment. To allow for the possibility that errors are heteroskedastic and correlated across time within a state, the standard errors for the estimated coefficients are adjusted for clustering by state.

\footnotetext{
${ }^{12}$ See, for example, Burkhauser, Couch, and Wittenburg (2000); Sabia (2009a,b); and Allegretto et al (2011).
} 
A key concern with the above empirical model is whether employment trends that are not accounted for by our controls differ systematically across states. While state fixed effects will control for differences across states that are fixed over time, employment trends that differ across states that are not accounted for by our controls could bias our results if the trends are correlated with state-specific trends in their cash wage. If, for example, states with unobserved factors leading to unusually high growth in restaurant employment also have higher (lower) than average growth in cash wages, the estimated effect of cash wages on employment will be biased upward (downward).

Our first approach to determine whether differences in unmeasured trends lead to a biased estimate of the cash wage effect on employment is to estimate models that include state-specific time trends. Second, we compare the earnings and employment effects of cash wages in two parts of the restaurant industry (full and limited service), and for two different occupations within the restaurant industry (tipped and non-tipped). Third, we estimate models of the difference in earnings or employment in the full and limited service restaurant industries.

The addition of state-specific time trends is designed to omit any bias that might emerge from spatial heterogeneity in employment trends that are correlated with state cash wage policies. Neumark et al (2012) point out several potential problems introduced by the inclusion of state specific time trends in their study of minimum wage effects on teen employment. The same issues are relevant in our study of the effect of higher cash wages. First, it is possible that state specific trends may be capturing some of the earnings or employment variation that is induced by tip credit laws. That is, higher cash wages could lead to a reduction in the trend rate of growth in the state after passage. Allowing for state-specific time trends may therefore capture some of the effect of higher cash wages on employment. Arguably, a preferable alternative to allowing for state-specific time trends would be the inclusion of a sufficiently rich set of control variables that would explain differences in the trend rate of growth across states. A second problem with adding state-specific trends is that it increases collinearity in the data, reduces the precision of estimated coefficients, and makes the results more sensitive to inclusion or exclusion of observations. Finally, inclusion of state-specific trends can make results sensitive to the choice of the sample period. 
This is especially important when there are recessions at the very beginning and end of the sample period. Excluding these recessions can substantially alter the estimates of the state-specific trends and thereby alter the estimated effects of variables that also exhibit a trend. ${ }^{13}$

The second approach for determining whether the estimated effects of cash wages are spurious is to test whether cash wages have an effect in the limited service restaurant industry. Since few workers in the limited service restaurant industry receive tips, a higher cash wage should have a negligible effect on labor cost and, therefore, generate little or no employment loss. In fact, it is possible that a higher cash wage could increase employment at limited service restaurants as customers and/or employers switch from full to limited service restaurants in response to an increase in the relative cost at full service restaurants.

The third approach we pursue is similar to the "triple-difference" approach described by Sabia et al. (2012) in their analysis of the effect of minimum wage hikes. To the extent that the full and limited service restaurant industry are affected by many of the unobservables, taking the difference between employment in the two industries will difference out the effect of any such unobservables. This will eliminate any bias caused by state-specific trends in unobservables that are common to the two sectors of the restaurant industry.

Finally, we explore falsification tests to determine whether our findings are spurious. In particular, we test whether higher cash wages have effects in industries or occupations that should be unaffected. A failure to find an effect in the other industries would be supportive evidence that our estimated effects in the full-service restaurant industry and for tipped workers are not spurious.

\section{Empirical Results.}

QCEW

${ }^{13}$ Neumark et al (2012) make this same point for studies of the employment effects of minimum wage increases. 
In this section, we examine the earnings and employment effects of minimum and cash wages using QCEW. As noted by Burkhauser et al. (2000), an important issue in empirically estimating the earnings or employment effects of minimum wages (or by extension, cash wages) is the high degree of collinearity between the minimum wage and the date and state fixed effects. If all states follow the federal law, the minimum and cash wage would be perfectly collinear with date fixed effects. Because there is interstate variation in the timing and size of the change in minimum and cash wages, there is some variation that can be used to identify earnings and employment effects. Despite the interstate variation in the minimum wage, the collinearity problem is still significant - for both the minimum wage and the cash wage. The collinearity problem is exacerbated with controls for state-specific time trends. ${ }^{14}$ In our case, the collinearity problem is further amplified by the fact that our models include both the minimum and cash wage as control variables, and 20 states link the cash wage to the minimum wage.

As an illustration of the collinearity problem in our data, we provide estimates of variance inflation factors (VIF) for the cash wage and minimum wage variables for different sample periods. The VIF for the cash wage is computed as $1 /\left(1-R^{2}\right)$ where $R^{2}$ is the r-squared from a regression of the $\log ($ cash wage) on all of the other control variables that will be included in the earnings and employment regressions. The VIF provides an index of how much the variance of estimated coefficients is increased because of collinearity. For example, if all of the right hand side variables are orthogonal to each other, $\mathrm{R}^{2}$ is zero and the VIF is unity. If there is perfect collinearity, the $\mathrm{R}^{2}$ is unity and the VIF is infinite.

\section{Earnings.}

$1{ }^{14}$ Allegretto, Dube, and Reich (2011) control for state-specific time trends and also allow Census region specific effects that differ by quarter. As noted by Neumark et al (2012), this introduces a very high degree of collinearity and the statistical significance of the estimated minimum wage effects disappear. Moreover, there is little evidence that states in the same census region are any better than states outside the census region as a control group for estimating the effects of minimum wage hikes. 
Table 1 presents the results of the QCEW earnings regressions. The dependent variable is the log of average weekly earnings per worker. For each sector in the restaurant industry (full and limited service), models are estimated with and without state-specific time trends. All the models include state and quarter fixed effects, along with controls for state-specific quarter-of-year effects, and a rich set of controls for factors that could affect restaurant employment in a state. These include log of population; the log of the employment-population ratio; the log of the state's personal income; the unemployment rate for the prime-age population; the percentage of the state's population that is under age 18 and the percentage over age 60; demographic controls describing the 25-60 year old population (female labor force participation rate, percent married; percent with college degrees); and average household size. Date fixed effects capture anything that influences restaurant employment nationally (e.g., business cycle, a changing propensity for families to dine out nationally, etc. $).{ }^{15}$ Unfortunately, we do not have a measure of hours per week in the QCEW, so we cannot estimate the average hourly wage. We also estimate a model with the difference between full and limited service earnings as the dependent variable to difference out the effect of unobservables that are common to both sectors of the restaurant industry.

As illustrated in figure 3, the full and limited service restaurant industries experienced significant declines in both employment and payroll during the recessions at the very beginning and end of our original sample period. Inclusion of these recessionary periods could result in estimates of state-specific trends that are not an accurate reflection of long term trends. To determine whether this affects the estimated effects of minimum and cash wages, the bottom panel of table 2 provides estimates with a

\footnotetext{
15 The source of state population data is http://www.census.gov/popest/. The annual data was converted into month data using a constant growth rate between each annual data point. The state employment data was obtained from the QCEW. The state personal income data was obtained from http://www.bea.gov. The Current Population Survey provided the unemployment rate for the prime-age population; the percentage of the state's population that is under age 18 and the percentage over age 60; demographic controls describing the prime-age (25-60) year old population (female labor force participation rate, percent married; percent with college degrees).,and average household size.
} 
sample period of 1994:1 through 2007:3 to remove the beginning and ending recessions. The estimates of the minimum and cash wage effects on weekly earnings are fairly robust to sample period. ${ }^{16}$

In all four specifications considered, higher cash wages (i.e., a reduction in the tip credit) increase weekly earnings in the full service restaurant industry, but have no statistically significant effect (at the .10 level) in the limited service restaurant industry. On the other hand, minimum wages have a positive effect on earnings in both full and limited service restaurants in all four specifications considered. In all specifications, the effect of higher minimum wages is greater at limited than full service restaurants, but the effects in the two sectors are significantly different from each other in only 2 of the 4 specifications. A larger effect in the limited service restaurant industry might be expected since the industry pays lower average wages and a larger share of their workers might be affected by minimum wage hikes. ${ }^{17}$

The minimum wage and cash wage effects on weekly earnings in the restaurant industry appear small. If there is no adjustment in hours worked, a 10 percent increase in the minimum wage should lead to a 10 percent increase in weekly earnings for minimum wage workers. It is important to keep in mind, however, that many workers in the restaurant industry are paid above the minimum wage and will be unaffected by minimum wage hikes. ${ }^{18}$ Also, for workers whose wages increase with the minimum wage, weekly earnings would increase by a smaller amount than the hourly wage if the employer cuts back on hours per worker.

Although the effect of an increase in the cash wage on weekly earnings in the full service restaurant industry is statistically significant at the .05 level, it is less than one-third of the effect of a

\footnotetext{
${ }^{16}$ The recession at the beginning of our sample ended in 1991:1 and the Great Recession at the end of our sample began in 2007:3. The ending date of 2007:3 was chosen to omit the Great Recession. The start date of 1994 was chosen because the model estimated for the entire period fits the data much better after 1994 than before. When the model without state-specific time trends is estimated for the full period, the average root mean squared error (rmse) is .077 for 1990:1 to 1993:4; .037 for 1994:1 through 2007:3; and .056 for 2007:4 to 2011:4. Moreover, the rmse shows a sharp rate of decline up until 1994 and a sharp increase after the onset of the great recession.

${ }^{17}$ According to the May 2011 Occupational Employment Survey data, the average hourly wages (including tips) in the full and limited service restaurant industry are $\$ 10.92$ and $\$ 9.71$, respectively.

${ }^{18}$ According to the Bureau of Labor Statistics (http://www.bls.gov/cps/minwage2011tbls.htm\#5 ), 22\% of workers in the leisure and hospitality industry are paid at or below the federal minimum wage. Since many states require a minimum above the federal level, a larger fraction of workers in the industry are paid at or below the relevant state minimum wage. Unfortunately, there is not a separate breakdown for limited and full service restaurants.
} 
higher minimum wage in all 4 specifications considered. It is important to put this in context. Suppose that the cash wage is $\$ 2.13$, the minimum wage is $\$ 7.25$, and the typical server is earning $\$ 2.13$ plus $\$ 10$ per hour in tips. If the cash wage is increased by 10 percent to $\$ 2.24$, this extra $\$ .21$ per hour would be only $1.7 \%$ of the server's $\$ 12.13$ earnings. On the other hand, if a dishwasher is paid $\$ 7.25$ per hour and the minimum wage increases by 10 percent, this a full 10 percent increase in the dish washer's hourly wage. Consequently, because higher cash wages affect only a portion of a tipped worker’s wages whereas the minimum wage affects all of a non-tipped worker's wage, we expect a smaller weekly earnings elasticity for the cash wage than the minimum wage.

The under-reporting of tips is another reason that the estimated effect of cash wages on earnings could be small. Employers in the restaurant industry have difficulty monitoring tips (particularly cash tips) and may be less concerned with under-reporting so long as employees report enough tips to meet the minimum wage requirement. If the cash wage is increased, the employer might not object if reported tips decline so long as there are sufficient tips reported to meet the minimum wage requirement. As a result, higher cash wages could cause actual earnings to increase more than reported earnings. Like the Internal Revenue Service (IRS), we have difficulty assessing the extent of this problem. ${ }^{19}$

\section{Employment.}

Estimates of employment effects in the QCEW are provided in table 2. The models include the same controls used in the earnings regressions presented in table 1. Cash wages are estimated to have a significant negative effect (.05 level) in the full service restaurant industry, but not in the limited service restaurant industry in 3 of the 4 specifications considered. The one exception is the model for the full sample period with state-specific time trends. In this one case, the cash wage has a small positive but

19 The IRS estimates that only between twenty and twenty-five percent of servers fully report tip income [Thomas 1994] and IRS data reveal that in 1988 tipped workers only reported about one-third of their tip income [Erard and Ho 2003]. 
statistically insignificant effect $(\mathrm{t}=0.16)$ in the full service restaurant industry, but a statistically significant positive effect in the limited service restaurant industry $(t=2.74)$. Since the sample period that excludes the recessions at the beginning and end of the 1990-2011 sample is likely to do a better job of capturing long term trends, we place greater faith in the estimates for the sample that excludes the recessions at the beginning and ending of the sample. Nevertheless, the sensitivity of the results to the selection of sample period is a matter of concern that we will address by considering alternative strategies.

By differencing employment in the full and limited service restaurant industries, any bias associated with trends in unobservables that have a common effect on employment in the two sectors of the restaurant industry can be eliminated. These results are presented in the right-most columns of table 2. In all four specifications considered, cash wages reduce employment in the full-service restaurant industry relative to the limited service restaurant industry. In each specification, the coefficients are statistically significant at the .10 or lower level. The one anomaly found in the earlier regressions (the full sample period with state-specific time trends) disappears in the difference equations.

Overall, the bulk of the evidence suggests that an increase in the cash wage has a relatively small effect on average weekly earnings. A 10 percent increase in the cash wage would increase average weekly wages by less than one percent in the full service restaurant industry, though the small increase in the average wage may mask larger increases for the subset of workers that receive tips. Similarly, higher cash wages reduce employment in the full service restaurant industry by a small amount. In the 3 models which we place greatest faith in (i.e. excluding the model with the beginning and ending recession and state-specific time trends), a 10 percent increase in the cash wage reduces employment by less than one percent. In the difference equations, a 10 percent increase in the cash wage reduces employment in the full service restaurant industry by less than one percent relative to that in the limited service restaurant industry.

While the estimated effects on earnings and employment may seem small, it is important to keep in mind that the bulk of the earnings and employment effects will be absorbed almost entirely by the group of tipped workers. Consequently, if tipped workers represent one-half of the workers in the full- 
service restaurant industry, the earnings and employment effects for this subgroup would be twice the size of those for the industry.

\section{CPS Data}

While the QCEW provides a very accurate measure of employment in the two sectors of the restaurant industry, it has two major shortcomings. First, it does not provide any information about hours worked. Consequently, if restaurants adjust both employment and hours to changes in the cash wage, the QCEW analysis could miss an important dimension of the response. Second, the QCEW does not provide any information on occupation making it impossible to focus on the group most likely to be affected by an increase in the cash wage - tipped workers.

While the CPS does not distinguish between full and limited service restaurants, it does provide information on the occupations of individual workers. Thus, within the restaurant industry, we can identify workers who are the most likely to be at full service restaurants and be eligible for tips. We use two different measures to gauge the fraction of each occupation that is tipped within the restaurant industry. The CPS provides two measures of hourly earnings: (1) hourly earnings excluding tips, overtime and commissions; and (2), hourly earnings including tips, overtime and commissions. To eliminate overtime from consideration, we restrict the sample to people who report usual work hours of 40 hours or less so that the difference between the two measures of earnings should reflect tips. Since earnings in the CPS are based on self-reports and workers probably under-report tips in the CPS, our estimates of the fraction of workers receiving tips is likely an understatement.

Another way to examine the frequency of tips is to compute the percentage of workers earning less than the minimum wage, excluding tips. An employee could earn less than the minimum wage because she is eligible for a tip credit, not covered by minimum wage law, or because the earnings are 
misreported. ${ }^{20}$ Some workers earning tips will not be at or above the minimum because either the employer chooses to pay a wage above the cash wage, or the worker resides in a state that doesn't allow a tip credit.

Table 3 presents these two different measures of tipping for the most common occupations in the restaurant industry. The three occupations with the highest tip rate are front-of-the-house jobs: waiters/waitresses, bartenders, and attendants (more commonly referred to as bussers or waiter assistants). For these occupations, the percentage of employees that are tipped ranges from a low of 33 percent (attendants) to a high of 68 percent (bartenders). On the other hand, back-of-the-house employees (i.e. those in the kitchen) all have substantially lower tip rates. For example, only 10 percent of cooks and 7 percent of dishwashers report tips. While one might not expect any of these back of the house employees to receive tips given the rules on mandatory tip-sharing, co-workers might voluntarily share tips or workers could have dual job duties and receive some tips (e.g. a cook might serve food on occasion to customers).

The ranking of occupation by the percentage paid less than the minimum is similar to the tip rate rankings. The front-of-the-house employees are more likely to be paid below the minimum than the back of the house. Overall, the data confirms our expectation that front of the house employees are more likely to receive tips and be eligible for a tip credit. Consequently, we expect increases in the cash wage to have a larger effect on workers in one of the three tipped occupations - waiters/waitresses, bartenders, and attendants.

To examine the effect of cash wages with CPS data, we aggregate the data by state to obtain an estimate of total tipped and non-tipped hours in the restaurant industry by quarter. We do not perform an analysis of earnings with CPS data since earnings information is only available for the outgoing rotation

\footnotetext{
${ }^{20}$ Federal law exempts businesses with less than $\$ 500,000$ in annual sales from the minimum wage. Also, federal law allows employers to pay a sub-minimum wage to workers under age 20 during the first 90 days of employment. See http://www.dol.gov/compliance/guide/minwage.htm\#who for a description of which jobs are covered by federal minimum wage laws.
} 
groups in the CPS and the sample sizes are one-fourth of what is available for usual hours worked and eliminating imputed earnings reduces sample sizes even further.

Estimates of log-hours regressions with CPS data are presented in table 4. The 4 specifications estimated with QCEW are repeated here for the log-hours of tipped workers, non-tipped workers, and the difference between the two. We control for the same list of control variables used in the QCEW.

In all four specifications, cash wages have negative effects on hours of tipped workers. The estimated elasticities range from -.12 to -.21 across the four specifications and are statistically significant at the .10 level in three of the four models. The model where statistical significance drops below .10 (tstatistic=-1.51) has the largest point estimate for the elasticity (-.21) but the largest standard error. The imprecision of the estimated effect here relative to the other specifications probably reflects a combination of a shorter sample period, the inclusion of state-specific time trends, and the highest degree of collinearity between the cash wage and the other control variables (VIF for the cash wage is 32.9 in this specification).

The CPS estimates of the cash wage effects are much larger than in the QCEW. Two differences between the QCEW and CPS analysis could explain this. First, unlike the QCEW, the CPS estimates are for tipped workers only and thus not diluted by including non-tipped workers who are unlikely to be affected by higher cash wages. Second, the CPS captures the effect of adjustments in both hours and employment, whereas the QCEW misses any adjustment in hours.

As a check on whether the estimates for tipped workers are spurious, we estimate the same models for non-tipped workers. In all four specifications considered, cash wages have no statistically significant effect (at the .10 level) on hours of non-tipped works. This is suggestive evidence that unmeasured trends affecting employment in the restaurant industry are not the source of a spurious relationship between cash wages and employment of tipped workers.

The difference equations for cash wages are not precisely estimated, particularly when statespecific time trends are included. The difference equations for all four specifications indicate that an increase in the cash wage reduces employment of tipped relative to non-tipped workers, but the estimated 
effects are statistically significant (.10 level) only in the two specifications that exclude state-specific time trends.

Overall, the CPS data indicate that higher cash wages reduce the employment of tipped workers, but have a negligible effect on non-tipped workers. The point estimates are less precise when statespecific time trends are included probably because of the greater degree of collinearity. Relative to the QCEW data, the estimated effects are larger in the CPS data, arguably because the CPS data is able to separate tipped from non-tipped workers and capture the effects of adjustments in both employees and hours per employee.

\section{Falsification tests.}

Thus far, the bulk of the evidence suggests that that higher cash wages reduce employment at full service restaurants and reduce the aggregate hours of tipped workers. The one nagging concern, however, is that allowing for unmeasured spatial heterogeneity in employment trends makes these results more fragile. This fragility might reflect the high degree of collinearity in the data that state-specific trends add, or it could be that the state-specific trends are controlling for unmeasured trends that are correlated with state-specific growth in cash wages.

To provide additional evidence on whether the estimated cash wage effects are spurious and capturing unmeasured trends, we re-estimate the model for other industries (QCEW) and occupations (CPS) where the cash wage should not matter. If we find that cash wages have a significant negative effect on employment in many industries (or occupations) where workers aren’t eligible for a tip credit, this would be strong evidence that our results for the full-service restaurant industry and tipped occupations are spurious.

For the QCEW, we choose the 81 other 2 digit industries available in the data. We estimate each of the earlier specifications with the same controls, the two sample periods, and with and without statespecific time trends. For each industry, we record the coefficient on the cash wage variable and the t- 
statistic. The results are presented in the top panel of table 5 for the four specifications. The results show that it is quite unusual to find an industry where the estimated cash wage effect has a statistically significant negative effect. In three of the four specifications, less than 5 percent of the t-statistics for the other industries are less than (i.e. more negative than) the t-statistic found for the full-service restaurant industry. Also, the median coefficient for the other 81 industries is much closer to zero. The one exception is the specification for the full sample period including state-specific time trends. In this case, 48 percent of the other industries have t-statistics below that that in the full-service industry. As noted earlier, this is the specification that we have the least faith in, however, because of the sensitivity of the estimated state-specific time trends to the inclusion of recessions at the beginning and end of the sample period and the model's poorer fit to the data over these recessions.

For the CPS, we identify 82 two-digit occupations and estimate hours regressions. For these occupations, we exclude workers in the restaurant industry in our calculation of aggregate hours. The same four specifications are estimated for all 82 two digit occupations. The results for the other occupations, summarized in the bottom half of table 5 , show that is quite rare to find an occupation where the cash wage effect is statistically significant. In three of the four specifications, the t-statistic is more negative than that found for the tipped occupations in less than 5 percent of the occupations. In the fourth specification (1994:1 to 2007:3) which includes state-specific time trends, less than 15 percent of the other occupations have a t-statistic that is more negative than that for tipped workers.

\section{Summary and Conclusions}

There is significant momentum among states to increase the cash wage requirement for tipped workers, and there is proposed federal legislation that would increase the federal cash wage. This study provides evidence on the effects of such policies and should help provide policy makers with useful 
information when considering the wisdom of such changes. Using data from the QCEW, we estimate that higher cash wages increase earnings for workers at full-service restaurants but reduce employment. Allowing for spatial heterogeneity of employment trends in the regression analysis makes the employment results more fragile, but we provide several pieces of evidence suggesting that the estimated cash wage effects are not spurious. For example, we show that higher cash wages do not affect employment in the limited services industry and that it is quite unusual to find a stronger negative effect in a sampling of other two digit industries.

The CPS data allowed us to focus on workers most likely to be affected by higher cash wages tipped workers. For this group, we find that higher cash wages reduce hours. We also find that nontipped workers are not affected by higher cash wages, and that it is unusual to find any other occupation where cash wages have a stronger negative effect than found for tipped workers.

While we believe the results provide fairly convincing evidence that higher cash wages increase earnings but reduce employment, like much of the minimum wage research, this study is confronted with the difficulties of separately identifying the true effect from a spurious relationship. A potential concern with the analysis is the sensitivity of the results to the inclusion of state-specific time trends when the recessions at the beginning and end of our sample period are included. Future research is needed to improve the degree of confidence in the statement that higher cash wages reduce employment. In particular, there is room for additional research that would focus on examples of cash wage increases in specific states using methods similar to those employed by other researchers to examine the effects of minimum wage hikes. 


\section{References}

Aaronson, Daniel and French, Eric. "Product Market Evidence on the Employment Effects of the Minimum Wage.” Journal of Labor Economics 25 (January 2007): 167-200.

; and McDonald, James. “The Minimum Wage, Restaurant Prices, and Labor Market Structure.” Journal of Human Resources, 43(Summer 2008) , p. 688-720.

Ahmed, Rebecca, "Legal Regulations of Tip Pooling and Tip Sharing in the United States Hospitality Industry" (2009). UNLV Theses/Dissertations/Professional Papers/Capstones. Paper 593. Available at http://digitalcommons.library.unlv.edu/thesesdissertations/593 .

Allegretto, Sylvia and Filion, Kai. "Waiting For Change: The \$2.13 Federal Subminimum Wage.” Economic Policy Institute and Center on Wage and Employment Dynamics Briefing Paper No. 297. February 2011.

Allegretto, Sylvia; Dube, Arindrajit; and Reich, Michael. "Do Minimum Wages Really Reduce Teen Employment? Accounting for Heterogeneity and Selectivity in State Panel Data” Industrial Relations 50 (April 2011): 205-240.

Anderson, John and Bodvarsson, Orn. "Do Higher Tipped Minimum Wages Boost Server Pay?" Applied Economics Letters 12 (Issue 7, 2005): 391-393.

Bureau of Labor Statistics. “Characteristics of Minimum Wage Workers: 2011.” March 2012. Available at http://www.bls.gov/cps/minwage2011.pdf .

Burkhauser, Richard V.; Couch, Kenneth A.; and Wittenburg, David C. "A Reassessment of the New Economics of the Minimum Wage Literature Using Monthly Data from the CPS,” Journal of Labor Economics 18 (October 2000): 653-680.

Card, David and Krueger, Alan B. "Minimum Wages and Employment: A Case Study of the Fast-Food Industry in New Jersey and Pennsylvania.” American Economic Review, 84(September 1994): 772-93.

. "Minimum Wages and Employment: A Case Study of the Fast-Food Industry in New Jersey and Pennsylvania: Reply." American Economic Review 90 (December 2000): 1397-1420.

Dube, Arindrajit; Lester, T. William; and Reich, Michael. "Minimum Wage Effects Across State Borders: Estimates Using Contiguous Counties.” Review of Economics and Statistics 92 (November 2010): 945-964.

Erard, Brian and Ho, Chih-Chin. "Explaining the US Income Tax Compliance Continuum." eJournal of Tax Research 1 (Issue 2, 2003): 93-109.

McConnell, Campbell R.; Brue, Stanley L.; and Macpherson, David A. Contemporary Labor Economics, $9^{\text {th }}$ edition. (New York, NY: McGraw-Hill Irwin, 2010). 
Neumark, David; Salas Ian J. M.; and Wascher, William. "Revisiting the Minimum Wage-Employment Debate:Throwing Out the Baby with the Bathwater?” Working Paper. September 2012.

Neumark. David, and Wascher, William L. Minimum Wages. (Cambridge, MA: MIT Press, 2008).

"Minimum Wages and Employment: A Case Study of the Fast-Food Industry in New Jersey and Pennsylvania: Comment.” American Economic Review 90 (December 2000): 1362-96.

Robinson, Terrence R. “A Comprehensive Look at the Tip Wage,” Compensation and Benefits Review 43 (July/August 2011): 214-219.

Sabia, Joseph J. "The Effects of Minimum Wage Increases on Retail Employment and Hours: New Evidence from Monthly CPS Data.” Journal of Labor Research 30 (March 2009): 75-97. (a)

“Identifying Minimum Wage Effects: New Evidence from Monthly CPS Data.” Industrial Relations 48 (April 2009): 312-328. (b)

.; Burkhauser, Richard V.; and Hansen, Benjamin. “Are the Effects of Minimum Wage Increases Always Small? New Evidence from a Case Study of New York State.” Industrial \& Labor Relations Review 65 (January 2012): 350-376.

Thomas, Paulette. “IRS Has Plan for Collecting Taxes on Tips.” Wall Street Journal (May 17, 1994): B1.

Wessels, Walter J. “The Minimum Wage and Tipped Employees.” Journal of Labor Research 24 (Summer 1993): 213-226.

•. “Minimum Wages and Tipped Servers.” Economic Inquiry 35 (April 1997): 334-349. 
Table 1. The Determinants of Average Weekly Wages in the Full and Limited Service Restaurant Industries.

Full Service Restaurants

Sample Period

Log Cash Wage

Log Minimum Wage

Log Population

Log

Employment/Population

Log Personal Income

\author{
1990:1 to 2011:4 1994:1-2007:3
}

$\begin{array}{cccc}0.0453 & 0.0373 & 0.038 & 0.032 \\ (4.00) & (2.75) & (3.21) & (2.80) \\ 0.152 & 0.152 & 0.156 & 0.125 \\ (5.27) & (7.04) & (5.48) & (5.43) \\ 0.0007 & 0.176 & -0.0136 & 0.169 \\ (0.01) & (1.71) & (-0.14) & (0.78)\end{array}$

Limited Service Restaurants

1990:1 to 2011:4 1991:2 to 2007:3

$\begin{array}{llll}-0.0103 & -0.0166 & 0.0040 & -0.0218\end{array}$

$\begin{array}{lll}(-0.69) & (-0.85) \quad(0.23)\end{array}$

0.222

(7.17)

0.202

$-0.132 \quad-0.127$

$(-0.63) \quad(-0.58)$

0.161

(3.34)

$-0.229$

$(-1.95)$

$(-1.59)$

0.154

(3.68)

0.0105

$(0.03)$

$0.127 \quad 0.309$

(0.67) (2.33)

0.0988

$(0.92)$

0.249

(1.26) (1.11) (0.79)

0.326

0.321

0.313

0.266

0.432

0.347

0.5

$(2.11)$

0.417

(4.74)

(3.31)
Full Service - Limited Service

1990:1 to 2011:4 1991:2 to 2007:3

$\begin{array}{cccc}0.0556 & 0.0538 & 0.034 & 0.0538 \\ (3.42) & (2.97) & (1.68) & (4.29) \\ \ddot{y} 0.070 & -0.0504 & -0.0057 & -0.0290 \\ (-2.25) & (-1.96) & (-0.11) & (-0.86) \\ 0.133 & 0.303 & 0.215 & 0.159 \\ (0.64) & (1.73) & (1.49) & (0.76)\end{array}$

$\begin{array}{llll}-0.0368 & -0.248 & -0.0410 & -0.0820\end{array}$

$\begin{array}{llll}(-0.21) & (-2.02) & (-0.35) & (-0.75)\end{array}$

$\begin{array}{llll}-0.106 & -0.0264 & -0.187 & -0.151\end{array}$

$\begin{array}{llll}(-0.60) & (-0.21) & (-1.77) & (-1.41)\end{array}$

State specific time trends included?

$\begin{array}{cccccccccccc}\text { No } & \text { Yes } & \text { No } & \text { Yes } & \text { No } & \text { Yes } & \text { No } & \text { Yes } & \text { No } & \text { Yes } & \text { No } & \text { Yes } \\ & & & & & & & & & & & \\ 4,488 & 4,488 & 2805 & 2805 & 4,488 & 4,488 & 2805 & 2805 & 4,488 & 4,488 & 2,805 & 2,805 \\ 0.986 & 0.991 & 0.980 & 0.987 & 0.958 & 0.971 & 0.960 & 0.974 & 0.394 & 0.597 & 0.384 & 0.609 \\ 0.356 & 0.217 & 0.257 & 0.189 & 0.307 & 0.420 & 0.235 & 0.126 & 0.0007 & 0.104 & 0.0226 & 0.0469 \\ 7.912 & 25.56 & 13.72 & 30.08 & 7.912 & 25.56 & 13.72 & 30.08 & 7.912 & 25.56 & 13.72 & 30.08 \\ 20.72 & 24.62 & 9.062 & 15.10 & 20.72 & 24.62 & 9.062 & 15.10 & 20.72 & 24.62 & 9.062 & 15.10\end{array}$

Note: The dependent variable is the log of average weekly wages (including any reported tip income) for workers in either the full-service or limited services industry.) The earnings variable is quarterly state-level data drawn from the Quarterly Census of Employment and Wages. Each regression also includes controls for the percent of the population over 60 , the percent under age 18, prime-age unemployment rate, average household size, and demographic controls describing the prime-age (25-60) year old population (female labor force participation rate, percent married; percent with college degrees). All of the t-statistics (provided in parentheses) are based on standard errors that are corrected for clustering at the state level. VIF is the variance inflation factor which is included as a gauge of the impact of collinearity on the standard error for the estimated coefficients. 
Table 2. The Determinants of Employment in the Full and Limited Service Restaurant Industries.

Sample Period

Log Cash Wage

Log Minimum Wage

Log Population

Log

Employment/Population

Log Personal Income

\section{Full Service Restaurants}

1990:1 to 2011:4 1994:1-2007:3

$\begin{array}{llll}-0.102 & 0.0036 & -0.0782 & -0.0294\end{array}$

$(-3.45)$

$-0.0524$

$(0.16)$

$(-3.13)$
-0.0145

$(-2.32)$

0.0529

$\begin{array}{llll}(-1.24) & (-1.70) \quad(-0.34) & (1.56)\end{array}$

0.858

(2.59)

0.0541

(0.28)

0.0350

(0.16)

0.926

0.97

1.039

(3.73)

0.816

(3.91)

0.0797

(6.27)

$-0.102$

$(-0.81)$

(0.44)

$-0.128$

$(-0.78)$

(3.67)

0.388

(2.55)

$-0.0241$

$(-0.17)$
0.0547

(0.21)

$(3.91)$
-0.208

$-0.208$

$(-0.87)$

Limited Service Restaurants

1990:1 to 2011:4 1991:2 to 2007:3

$\begin{array}{ll}-0.0230 & 0.0791\end{array}$

$(-0.76)$

(2.74)

$-0.0154 \quad 0.0088$

$(-0.56) \quad(0.39)$

$-0.0945$

0.0004

$(-2.86) \quad(-2.94)$

0.92

1.648

$(-1.52)$

0.961

(3.47)

0.0621

(0.01)

1.458

(3.56)

0.353

(0.25)

$-0.127$

(2.07)

-0.0557
$(-0.21)$
Full Service - Limited Service

1990:1 to 2011:4 1991:2 to 2007:3

$\begin{array}{llll}-0.0788 & -0.076 & -0.0628 & -0.0382\end{array}$

$\begin{array}{llll}(-2.34) & (-2.38) & (-1.65) & (-1.75)\end{array}$

$\begin{array}{llll}0.138 & 0.111 & 0.0799 & 0.0525\end{array}$

$\begin{array}{llll}(2.12) & (1.72) \quad(1.04) \quad(0.81)\end{array}$

$\begin{array}{llll}-0.0640 & -0.724 & 0.0089 & -0.418\end{array}$

$\begin{array}{llll}(-0.30) & (-3.03) & (0.05) & (-1.00)\end{array}$

$\begin{array}{llll}-0.115 & 0.0615 & 0.0173 & 0.0346\end{array}$

$\begin{array}{llll}(-0.56) & (0.27) \quad(0.09) & (0.209)\end{array}$

$\begin{array}{llll}-0.0185 & 0.108 & -0.0008 & 0.0320\end{array}$

$(-0.11) \quad(0.51) \quad(-0.00) \quad(0.12)$

State specific time trends included?

$\begin{array}{cccccccccccc}\text { No } & \text { Yes } & \text { No } & \text { Yes } & \text { No } & \text { Yes } & \text { No } & \text { Yes } & \text { No } & \text { Yes } & \text { No } & \text { Yes } \\ & & & & & & & & & & & \\ 4,488 & 4,488 & 2805 & 2805 & 4,488 & 4,488 & 2805 & 2805 & 4,488 & 4,488 & 2,805 & 2,805 \\ 0.935 & 0.978 & 0.934 & 0.974 & 0.847 & 0.934 & 0.776 & 0.903 & 0.532 & 0.751 & 0.574 & 0.782 \\ 0.931 & 0.972 & 0.962 & 0.970 & 0.954 & 0.952 & 0.959 & 0.951 & 0.008 & 0.044 & 0.02 & 0.034 \\ 7.912 & 25.56 & 13.72 & 30.08 & 7.912 & 25.56 & 13.72 & 30.08 & 7.912 & 25.56 & 13.72 & 30.08 \\ 20.72 & 24.62 & 9.062 & 15.10 & 20.72 & 24.62 & 9.062 & 15.10 & 20.72 & 24.62 & 9.062 & 15.10\end{array}$

Note: The dependent variable is the log of state employment for workers in either the full-service or limited services industry. The earnings variable is quarterly state-level data drawn from the Quarterly Census of Employment and Wages. Each regression also includes the same list of controls listed at the bottom of table 1. All of the t-statistics (provided in parentheses) are based on standard errors that are corrected for clustering at the state level. VIF is the variance inflation factor which is included as a gauge of the impact of collinearity on the standard error for the estimated coefficients. 
Table 3

Percent of Workers Reporting Tips for Restaurant by Occupation: 2006-2011

$\begin{array}{lccc}\text { Share of Workers } & \text { Percent Tipped } & \begin{array}{c}\text { Percent Hourly Wage Less } \\ \text { than Minimum Wage }\end{array} \\ \begin{array}{l}\text { Industry } \\ \text { Tipped Occupations }\end{array} & 100 \% & 27 \% & 20 \% \\ \quad \text { Wait Staff } & 26 \% & 61 \% & 44 \% \\ \text { Bartender } & 3 \% & 68 \% & 37 \% \\ \text { Attendants } & 3 \% & 33 \% & 25 \% \\ \text { All } & 32 \% & 59 \% & 42 \% \\ \text { Non Tipped Occupations } & & & \\ \text { Cashier } & 9 \% & 8 \% & 11 \% \\ \text { Cook } & 31 \% & 10 \% & 10 \% \\ \text { Dishwasher } & 3 \% & 7 \% & 14 \% \\ \text { Food Service Manager } & 10 \% & 15 \% & 18 \% \\ \text { Counter Attendant } & 4 \% & 10 \% & 14 \% \\ \text { All Other Non-Tipped } & 13 \% & 21 \% & 10 \% \\ \text { All } & 69 \% & 12 \% & \end{array}$

Note: Estimates are based upon CPS data from January 2006 through December 2011. Workers reporting any overtime, tips, or commissions are defined as tipped. The sample is restricted to workers reporting 40 or fewer hours per week to avoid counting workers receiving overtime as tipped workers. The percentage of workers with an hourly wage below the state's minimum wage is based upon the hourly wage that excludes tips, overtime, and commissions. 
Table 4. Determinants of Total Hours Employed for Tipped and Non-Tipped Workers in Restaurant Industry.

Sample Period

Log Cash Wage

Log Minimum Wage

Log Population

Log

Employment/Population

Log Personal Income

State specific time trends included?

Observations

Within Group $\mathrm{R}^{2}$

Overall $\mathrm{R}^{2}$

VIF Cash Wage

VIF Minimum Wage
Hours of Tipped Workers

1990:1 to 2011:4 1994:1-2007:3

$-0.102$

$(-3.45)$

$-0.0524$

0.0036

$(0.16)$
-0.0456

$-0.0782$

(-3.13)

$(-3.13)$
-0.0145

$-0.0294$

$(-2.32)$

$(-1.24)$

$(-1.70)$

$(-0.34)$

0.0529

0.858

0.926

(3.73)

0.97

(3.91)

0.0797

0.0541

(0.28)

0.0350

0.816

$(0.44)$

$-0.102$

$-0.128$

$(-0.78)$

(1.56)

1.039

(3.67)

0.388

(2.55)

$-0.0241$

$(-0.17)$

0.0547

$(0.21)$

Hours of Non-Tipped Workers

1990:1 to 2011:4 1991:2 to 2007:3

$\begin{array}{ll}-0.0230 & 0.0791\end{array}$

$(-0.76) \quad(2.74)$

$-0.191$

$(-2.86)$

0.92

(2.98)

0.168

$-0.157$

$-0.0154 \quad 0.0088$

$(-0.56) \quad(0.39)$

$-0.0945$

0.0004

$(-2.94)$

$(-1.52)$

0.961

(5.98)

0.752

(3.47)

0.0621

(0.01)

1.458

1.458
$(3.56)$

0.353

(3.91)

(0.25)

$-0.208$

$-0.127$

(2.07)

$-0.0557$

$(-0.55) \quad(-0.21)$

$-0.0185$

$(-0.11)$

No

$$
\text { No }
$$

4,488

Yes

No

4,488
0.978

2805

Yes

0.934

2805

0.974

0.931

0.972

0.962

0.970

13.72

30.08

15.10

$\begin{array}{cc}\text { No } & \text { Yes } \\ & \\ 4,488 & 4,488 \\ 0.847 & 0.934 \\ 0.954 & 0.952 \\ 7.912 & 25.56 \\ 20.72 & 24.62\end{array}$

No

2805

Yes

No

4,488

0.532

0.008

0.959

13.72

9.062

30.08

15.10

7.912

20.72

Tipped - Non-Tipped

1990:1 to 2011:4 1991:2 to 2007:3

Note: The dependent variable in all the regressions is log of hours. The estimates of hours are based upon aggregation of monthly CPS data to quarterly state-level data. Tipped workers include servers, attendants and bartenders in the restaurant industry. Non-tipped workers include all other workers in the restaurant industry. The regressions also include the same list of controls described in table 1. All of the t-statistics (provided in parentheses) are based on standard errors that are corrected for clustering at the state level. VIF is the variance inflation factor which is included as a gauge of the impact of collinearity on the standard error for the estimated coefficients. 


$\begin{array}{cccc}\text { No state - } & \text { State-specific } & \text { No state - } & \text { State-specific } \\ \text { specific } & \text { time trends } & \text { specific time } & \text { time trends } \\ \text { time trends } & \text { included } & \text { trends } & \text { included }\end{array}$

\section{QCEW}

coefficient on cash wage for full service restaurants

$-0.10$

$-3.45$

t-statistic for full service restaurants

median coefficient for 81 other industries

$-0.03$

$-0.50$

median t-statistic for 81 other occupations

$1.2 \%$

0.004

0.16

0.01

0.18

$48.1 \%$

$-0.08$

$-3.13$

$-0.02$

$-0.39$

$2.50 \%$

$-0.03$

$-2.13$

$-0.001$

$-0.06$

$4.9 \%$

\section{CPS}

coefficient on cash wage for tipped workers

median coefficient for 82 other occupations

$-0.17$

$-0.02$

$-2.17$

t-statistic for tipped workers

median t-statistic for 82 other occupations

$-0.20$

$2.4 \%$
$-0.12$
$-0.06$
$-1.71$
$-0.37$
$4.9 \%$

$-0.18$

0.00

$-1.72$

0.012

$2.4 \%$
$-0.21$

$-0.03$

$-1.51$

$-0.15$

$13.4 \%$

Note: Results represent estimated effect of cash wage on log-employment (QCEW) or log-hours (CPS). The QCEW regressions are identical to those in table 2 for the full-service restaurants, except that the log-employment measure is for 81 non-restaurant industries. Regressions for the CPS are identical to those in table 4 for tipped and non-tipped workers except that aggregate hours for 82 occupations that are not counted as either tipped or non-tipped occupations - excluding any hours that are in the restaurant industry. All of the t-statistics (provided in parentheses) are based on standard errors that are corrected for clustering at the state level. 


\section{Figure 1.}

\section{Number of States With Cash Wage Above Federal Requirement.}

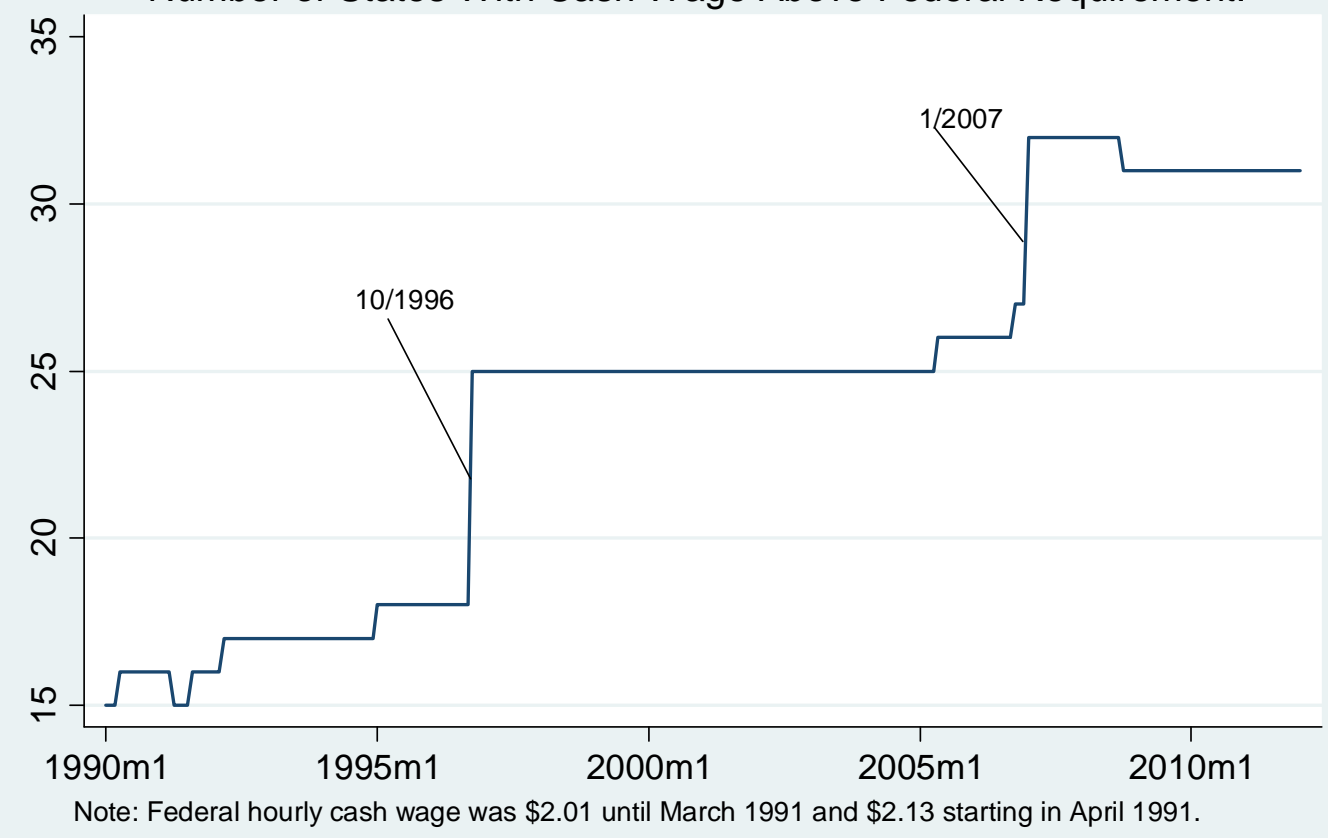

Figure 2.

Average Cash Wage: 1990-2011.

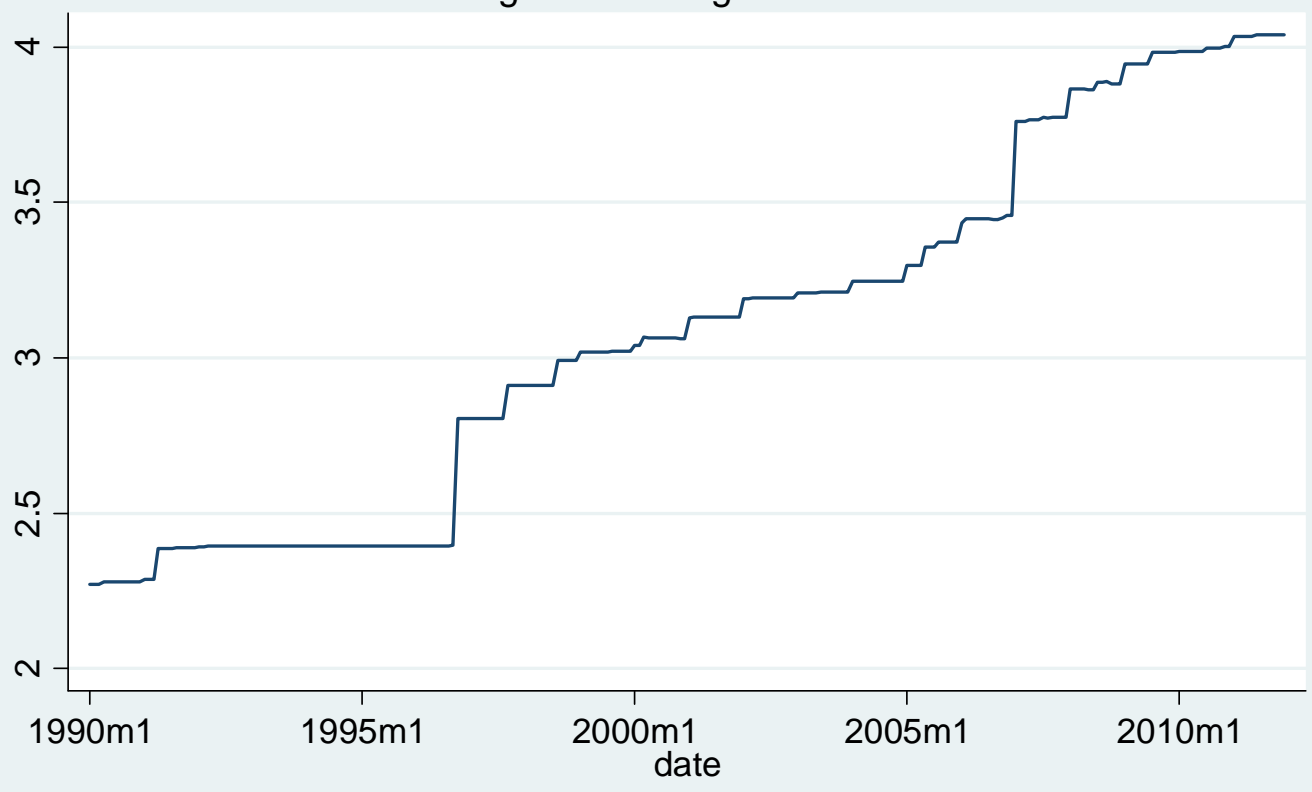

Note: Averages are calculated using state populations as weights. 